\title{
CSF Biomarkers
}

\author{
Alessandra Piccini*
}

Unit of Geriatric Medicine, Department of Internal Medicine and Medical Specialties, University of Genoa, Genoa, Italy

\begin{abstract}
With an ever growing population of aged individuals who are at risk of developing Alzheimer's disease (AD), there is an urgent need for a sensitive, specific and preferably non-invasive diagnostic standard of disease progression. Diagnosis of AD is still largely based on exclusion criteria of secondary causes and other forms of dementia with similar clinical pictures, than the diagnostic accuracy of $\mathrm{AD}$ is low. Recent research focused the attention to biochemical diagnostic markers (biomarkers) as they are very important indicators of normal and abnormal biological processes. Molecular aberrations in the AD brain are reflected in the cerebrospinal fluid (CSF) where three candidate biomarkers have recently been identified: total tau protein, amyloid $\beta$-protein 1-42 and tau protein phosphorylated at AD-specific epitopes. The sensitivity and specificity of these data are able for discrimination of AD patients from controls. Here, we review the recent literature on biochemical biomarkers and discuss their predictive value as indicative for disease vulnerability to detect individuals at risk for $\mathrm{AD}$ and to determine the clinical efficacy of novel, disease-modifying strategies. According to the literature analysis reported in the present review, we can conclude that the combination of the CSF biomarkers and their ratios may significantly increase the specificity and the accuracy of AD diagnosis.
\end{abstract}

Keywords: Alzheimer's disease, cerebrospinal fluid, biomarker, tau protein, amyloid $\beta$-protein.

\section{INTRODUCTION}

Alzheimer's disease (AD) is the most common cause of dementia among elderly people and will become a public health crisis within two to three decades if left untreated. The onset of disease is not manifested clinically and little is known regarding the cause of non-familiar AD. Diagnosing $\mathrm{AD}$ and distinguishing it from other dementias depends primarily on clinical evaluation, and, ultimately, on investigator judgment [1]. This procedure is time consuming and costly, requiring neurological examinations, neuropsychological testing, neuroimaging, and blood investigations. There is also no definite clinical method to determine which patients with mild cognitive impairment (MCI) will develop $\mathrm{AD}[2,3]$. A definitive diagnosis of $\mathrm{AD}$ can only be made after death, when autopsy can reveal senile plaques and neurofibrillary tangles in brain tissue. Therefore, there is an urgency to develop a novel promising biomarker for early diagnosis of $\mathrm{AD}[2]$.

Indeed, the prevailing diagnostic standards in research for $\mathrm{AD}$, the NINCDS-ADRDA criteria, are now being revised in order to introduce neurobiological measures on to the clinically based criteria [4]. The new criteria are centred on a clinical core of early and significant episodic memory impairment and there must also be at least one or more abnormal biomarkers among structural neuroimaging with MRI, molecular neuroimaging with PET, and cerebrospinal fluid analysis of beta-amyloid (A $\beta)$ or tau proteins [4]. These proposed criteria move away from the traditional approach of first identifying dementia according to degree of

*Address correspondence to this author at the Unit of Geriatric Medicine, Department of Internal Medicine and Medical Specialties, University of Genoa, Viale Benedetto XV 6, 16132 Genoa, Italy; Tel: +39-010-3538881; Fax: +39-010-506938; E-mail: alex_00141@yahoo.com functional disability, rather they aim to define the clinical, biochemical, structural and metabolic presence of AD.

The testing and ultimate implementation of emerging therapies will require identification of affected and "at-risk" individuals to target them for clinical trials, and to direct and monitor therapy. Thus, fluid and neuroimaging measures are being explored as possible biomarkers for early-stage and pre-clinical $\mathrm{AD}$ diagnosis because it is in these initial stages that disease-modifying therapies are likely to have the greatest chance of preserving normal brain function. Much focus has therefore been directed on patients with MCI, which is a syndrome characterized by cognitive impairment but not severe enough to fulfil the criteria for dementia [5]. Even though around $40-60 \%$ of patients with MCI develop $\mathrm{AD}$ during the first 5 years, many have a stable form of memory impairment [6,7]. Moreover, early stages of vascular dementia or dementia with Lewy bodies, for example, can be preceded by MCI [7].

Although there are currently no proven therapies that delay the onset or prevent the progression of $\mathrm{AD}$, several promising candidates are being developed. Biochemical changes in the brain are reflected in the cerebrospinal fluid (CSF), and intense research efforts have been made to develop biomarkers for the central pathogenic processes in $\mathrm{AD}$ that can be used as diagnostic tools. Early studies indicated that CSF biomarkers could be useful for defining a subgroup of patients with MCI at especially high risk of developing $\mathrm{AD}$ [8-10]. The best studied fluid proteins in $\mathrm{AD}$ have been CSF levels of $A \beta 42$, the primary constituent of amyloid plaques, and tau protein, the primary component of neurofibrillary tangles. Levels of CSF A $\beta 42$ are typically reduced in $\mathrm{AD}$ [11-13] reflecting its aggregation and deposition as amyloid in the brain [14], whereas levels of CSF tau and phosphorylated tau (p-tau) species are increased 
in $\mathrm{AD}[15,16]$ and are hypothesized to reflect the presence of neurofibrillary tangles, neurodegeneration, or both [17, 18] although not all studies support this conclusion [19]. Indeed, there is no proof that plaque formation is reason for $\mathrm{A} \beta$ concentration decrease, only correlation. A tau protein/A 342 index, usually increased in $\mathrm{AD}$ patients, has high sensitivity, high specificity and also high negative predictive value in $\mathrm{AD}$ diagnosis [20].

The assessment of these markers can also contribute to the differential diagnosis of vascular dementia, but also other forms of primary degenerative dementia (e.g., a frontotemporal dementia). Therefore, the availability of biochemical markers that, at least in part, replace the clinical procedures, is highly desirable.

\section{AMYLOID- $\beta$}

The discovery that $\mathrm{A} \beta$ peptide forms the main component of $\mathrm{AD}$ plaques primarily with a length of 42 amino acids [21] and that it is secreted by cells [22] led to investigations of A 342 in the CSF for AD. A large number of studies have been conducted on patients and controls, showing a reduction of $\mathrm{A} \beta 42$ by about $50 \%$ in $\mathrm{AD}$ patients compared with non-demented controls of the same age; the diagnostic sensitivity and specificity levels ranged between $80 \%$ and $90 \%$ [8]. An autopsy study demonstrated an inverse correlation between $A \beta 42$ levels in the CSF and the number of plaques [23]. Reduction in CSF A $\beta 42$, likely reflecting $A \beta$ aggregation in the brain, is associated with brain atrophy in the pre-clinical phase of $\mathrm{AD}$ [24]. This suggests that there is toxicity associated with $A \beta$ aggregation before the onset of clinically detectable disease. Thus, CSF A $\beta 42$ may be considered a useful biomarker for the presence of amyloid plaques regardless of clinical status. However, since some neurodegenerative diseases present with low CSF A $\beta 42$ levels in the absence of plaques, other reasons for the reduced CSF A $\beta 42$ levels in AD cannot be ruled out. Recently, it was found that multiple sclerosis goes with reduced CSF $A \beta 42$, which is probably caused by upstream downregulation of $\beta$-secretase (BACE1) and amyloid precursor protein (APP) expression secondary to neuroinflammation [25]. Furthermore, reductions in CSF A 342 values reflect the presence of amyloid plaques but perhaps also diffuse nonfibrillar plaques and/or concomitant $\mathrm{A} \beta$ oligomer formation, both of which could contribute to neurotoxicity [26]. Promising studies using unconventional methods suggest that $A \beta$ oligomers can be measured in CSF in the femtomolar range $[27,28]$.

Since CSF levels of the shorter A $\beta 40$ isoform are unchanged or increased in $\mathrm{AD}$, it has been also proposed that measurement of the $A \beta 42 / A \beta 40$ ratio might be more accurate to $A \beta 42$ alone $[12,29-32]$, even in early stage disease [33]. Moreover, the discovery of shorter A $\beta$ isoforms in brain and CSF has made it clear that $\mathrm{A} \beta$ constitutes a large family of peptides with considerable length variations [34]. The shorter peptides likely result from the ability of BACE1 and $\gamma$-secretase to execute catalytic cleavages at different positions in APP, as well as the probable involvement of other APP- and A $\beta$-degrading proteases. More studies are needed to determine the clinical value of CSF measurements of detailed $A \beta$ peptide patterns, as compared to CSF A $\beta 42$ alone.
Recently, a method based on stable isotope labeling and mass spectrometric analysis of immunocaptured $A \beta$ was presented [35]. This technique allows for determination of production and clearance rates of total A $\beta$ in CSF and plasma and may help addressing the fundamental question if patients who develop $\mathrm{AD}$ have increased production or decreased clearance of the peptide.

\section{TAU PROTEIN}

The main component relating to intraneuronal changes in $\mathrm{AD}$ patients is the microtubule-associated tau protein. In $\mathrm{AD}$ patients, tau protein is present in a pathologic, hyperphosphorylated form. Tau pathology is also characteristic of other neurodegenerative diseases, but it differs from tau pathology in AD patients at the molecular level [36]. Initially all forms of tau, regardless of their phosphorylation status, were quantified in the CSF involving that they are released extracellularly as a result of the neurodegenerative process. Numerous studies have demonstrated an increase in the concentration of total tau (t-tau) in AD patients by approximately $300 \%$ compared with non-demented elderly subjects, and a systematic increase in the concentration with age was observed in the control groups [37,38].

Using monoclonal antibodies specific for different phosphorylated epitopes of tau, enzyme-linked immunosorbent assays have been developed that sensitively measure concentrations of phosphorylated tau protein (p-tau) in CSF. Indeed, most of the studies to date have investigated tau protein hyperphosphorylated at threonine 231 (p-tau 231P) and at threonine 181 (p-tau 181P), and a few results have been obtained for serine 199 ( $\mathrm{p}$-tau 199P). Differences have certainly been observed between the individual $p$-tau subtypes: p-tau $231 \mathrm{P}$ and $\mathrm{p}$-tau $181 \mathrm{P}$ show better results than p-tau 199P in distinguishing AD from control groups [39]. Furthermore, p-tau 231P significantly improved differential diagnosis between $\mathrm{AD}$ and other non-AD groups, particularly frontotemporal dementia [40], and p-tau 181P has been proposed as a potential marker for discriminating patients with $\mathrm{AD}$ from those with dementia with Lewy bodies [39].

Concentrations of all $3 \mathrm{p}$-tau proteins are equally significantly increased in patients with AD [39-44]. Thus, the high negative predictive value of $\mathrm{p}$-tau of approximately $90 \%$ appears to be particularly significant meaning that normal values rule out the presence of AD with almost $90 \%$ probability [45].

\section{RATIO A $\beta / T A U$}

The development of refined assays improved the separation of $\mathrm{AD}$ from other dementias but did not improve the sensitivity of detecting $\mathrm{AD}[44,46]$. Thus, it has been investigated the diagnostic usefulness of the CSF ratio of $p$ tau to $A \beta 42$ instead measuring alone. It is now well established that CSF $A \beta 42$ or CSF $A \beta 42 / A \beta 40$ in conjunction with $\mathrm{t}$-tau and $\mathrm{p}$-tau, that reflect the axonal degeneration in $\mathrm{AD}$ [47], identify and predict $\mathrm{AD}$ with sensitivity and specificity of $80-95 \% \quad\left[\begin{array}{ll}9, & 48-51] \text {. }\end{array}\right.$ Measurement of the CSF ratio of $p$-tau to $A \beta 42$ provides a biochemical diagnostic aid that may replace some of the current clinical investigational efforts and thereby speed up the diagnostic procedure and reduce its cost. Measurement of 
the CSF ratio of $p$-tau to $A \beta 42$ may also constitute a tool for monitoring disease progression, which has to be investigated within a longitudinal design.

CSF analyses of t-tau, p-tau $181 \mathrm{P}$ and $\mathrm{A} \beta 42$ are strong and independent risk markers for development of clinical $\mathrm{AD}$ in patients with MCI $[9,48,50,52,53]$. Namely, CSF high p-tau 231P levels at baseline correlated with the rate of cognitive decline in Mini-Mental State Examination scores in patients with MCI [39]. In agreement with the analysis of rates of cognitive decline, increased levels of p-tau 231P correlated with conversion to $\mathrm{AD}$ [39]. A recent European multicenter trial on CSF p-tau 231P in MCI subjects has shown that the results for $\mathrm{p}$-tau in predicting $\mathrm{AD}$ in this risk group are indeed stable and consistent throughout multiple centers [54]. In this study p-tau proved to be a powerful candidate predictor of $\mathrm{AD}$ in MCI subjects even in a very short mean observation interval of only 1 to 2 years [54].

Besides, it has been demonstrated that the association of all the different combinations of these CSF biomarkers with incipient $\mathrm{AD}$ was much stronger than, and independent of, other established risk factors such as age, sex, education, $A P O E$ genotype, plasma homocysteine, blood pressure, and low performance on brief cognitive tests [48]. All these studies suggest that a useful combination of biomarkers might optimize prediction in a more heterogeneous MCI population during a longer observation period, however, more studies are needed to establish which combination has the best performance.

\section{NOVEL APPROACHES}

Several biomarkers for neurodegenerative diseases have been identified in past studies, which include APP, cathepsin $B$ precursor [55] and $\beta$-fibrinogen plus Vitamin D-binding protein or ceruloplasmin for $\mathrm{AD}$ [56]. Recently, it has also been suggested that signaling proteins in blood plasma can be used to differentiate AD from control subjects [57]. Unfortunately, however, the sensitivity and specificity of any of these identified markers, either alone or in combination, is insufficient to merit routine clinical use [58]. Thus, analysis of proteins in CSF as new clinically useful biomarkers is of great diagnostic importance.

Cystatin $\mathrm{C}$ is another marker that has been investigated for the diagnosis of neurodegenerative diseases [59]. This amyloid protein occurs along with $A \beta 42$ in the walls of the arterioles in patients with $\mathrm{AD}$ and binds $\mathrm{A} \beta$ inhibiting its fibril formation [60]. It seems that very low concentrations of cystatin $\mathrm{C}$, both in the CSF and serum of AD patients, are caused by its accumulation in the reactive astrocytes before amyloid formation [20]. Some authors reported no statistically significant differences between the cystatin $\mathrm{C}$ levels in the serum and the CSF in AD and vascular dementia patients when compared to other patients $[20,61]$. On the contrary, other studies $[62,63]$ reported that serum cystatin $\mathrm{C}$ levels decrease in $\mathrm{AD}$ patients. Lower serum levels of cystatin $\mathrm{C}$ has also been associated with higher incidence of $\mathrm{AD}$ in elderly men free of dementia at baseline suggesting cystatin $\mathrm{C}$ as a marker of future risk of AD [64]. This finding hypothesizes that low serum cystatin $\mathrm{C}$ levels precede clinical $\mathrm{AD}$ and, possibly, mirror a reduced ability to inhibit neuronal $A \beta$ aggregation [64]. Thus, further studies are needed to investigate this important issue even though, due to these controversial studies, cystatin $\mathrm{C}$ probably will not become a new "revolutionary" marker contributing to the differential diagnostics.

Recently, it has been characterised in the CSF and brain of $\mathrm{AD}$ the presence of $\mathrm{S} 100 \mathrm{~A} 7$ [65], a protein previously implicated in inflammatory responses and cell differentiation [66]. S100A7 content is elevated in the CSF of AD dementia cases compared to neurological control cases, and these elevated S100A7 levels in the CSF selectively identify AD clinical severity [65]. It seems that S100A7 attenuate AD amyloid neuropathology through promotion of the "nonamyloidogenic" $\alpha$-secretase processing of APP. Thus S100A7 could be a biomarker that quickly diagnoses AD before clinical signs have developed, allowing for early symptomatic treatment.

Neuronal pentraxin receptor (NPR) and $\alpha$-dystroglycan and $120 \mathrm{kDa}$ isoform precursor of neural cell adhesion molecule 1 (NCAM-120) have been also identified as candidate biomarkers for neurodegenerative diseases [67]. More importantly, NPR has been found to be a candidate biomarker specific for $\mathrm{AD}$ [67]. However, large-scale validation studies need to be performed to confirm the association between NPR and AD and also to understand how and whether NPR participates in the pathogenesis of AD.

A particularly promising new approach in the CSF focuses on the detection and quantification of BACE1, one of the key enzymes responsible for the pathologic amyloidogenic cleavage of the APP. A significant increase was found in BACE1 concentration and activity in the CSF of MCI subjects compared with healthy controls [68].

Finally, isoprostanes are also being studied as candidate markers of lipid peroxidation. An increase was found in the CSF of MCI subjects compared with controls, and isoprostanes and p-tau performed better than memory tests [24]. The isoprostanes even improved the results obtained with hippocampal volumetry to distinguish between the groups [69]. However, because of the very demanding analysis method, isoprostanes should still be regarded as a merely scientific approach.

In recent years, there has been a growing interest in applying proteomics to research on clinical diagnostics and predictive medicine of neurodegenerative disorders [70]. Proteomics enables the study of many proteins simultaneously and can thereby unravel pattern of changes in neurodegenerative disorders, e.g. patterns that are disease specific. Proteomic profiling of cerebrospinal fluid provided a novel panel of potential biomarkers for prediction of MCI progression to $\mathrm{AD}$ and for the differential diagnosis of $\mathrm{AD}$ versus normal aging and frontotemporal dementia [71-74].

Many efforts have also focused on serum and CSF levels of antibodies to $A \beta$ that naturally are found in the CSF and plasma of patients with $\mathrm{AD}$ as well as healthy control subjects [75]. To date, differences between diseased and control subjects has been highly variable especially because, in biological fluids, antibodies and antigens are in a state of dynamic equilibrium between bound and unbound forms that is concentration dependent. Namely, there is a recent study that demonstrates the relevance of measuring bound and unbound antibody against $A \beta$ in serum of patients affected 
by $\mathrm{AD}$ [75]. This finding suggests that dissociated $\mathrm{A} \beta$ antibody levels are of significant diagnostic value at the onset of the neurodegenerative process and, thereafter, may be a useful biomarker for disease progression.

\section{CONCLUSION}

As disease-modifying therapies for $\mathrm{AD}$ are being developed, there is great need to identify biomarkers that will serve as surrogates of underlying disease pathology. In the eventual clinical setting, such biomarkers may be used to improve the accuracy of clinical diagnosis and to track disease progression. As an immediate application, biomarkers may be useful in the design and evaluation of clinical trials; for example, to assess the effect of a therapy on its intended target in early phase studies, to optimize patient enrollment in prevention trials and to track disease progression.

Intense research has led to the development of CSF biomarkers reflecting different aspects of AD pathogenesis. Currently, validated and reliable biomarkers exist for amyloid pathology and Alzheimer-type axonal degeneration. Measuring CSF A $\beta 42$, t-tau and p-tau alone or in combination may be especially useful for the selection of pre-symptomatic individuals with known pre-clinical AD pathology for enrollment in prevention trials of diseasemodifying therapies. Furthermore, reliable methods to measure $A \beta$ oligomers that may be specifically related to $A D$ onset and progression would be a valuable tool in $\mathrm{AD}$ diagnostics. There are also indications that the ratios of various $A \beta$ peptides improve the neurochemical profile for potential diagnostic applications $[76,77]$.

A potential limitation for the widespread use of CSF biochemical markers in general practice lies in collecting $\mathrm{CSF}$ at lumbar puncture. However, the technique of lumbar puncture has considerably improved and, as a consequence, the incidence of headache after lumbar puncture in elderly patients is $2 \%$ or less [78]. The evaluation of CSF A $\beta 42, t-$ tau, and p-tau in memory clinics will result in some falsepositive cases, as well as false-negative cases, and the biomarkers may therefore be useful primarily as screening tools, selecting individuals for a detailed further clinical follow-up. Moreover, they may be useful in enriching study populations for clinical trials of future disease-modifying $\mathrm{AD}$ treatments.

It is unrealistic to expect that both sensitivity and specificity could be set at a level higher than $90 \%$ by measuring $A \beta$ peptides and tau proteins alone, because postmortem analyses of brains with $\mathrm{AD}$ revealed a variety of additional lesions, such as infarcts, gliosis, argyrophilic grains, and Lewy bodies. In addition, other dementing conditions display at least some neuropathological features that overlap $\mathrm{AD}$, such as tau-positive filamentous lesions. In the future, a biochemical marker pattern reflecting the whole spectrum of abnormal proteins deposited in the brain will most likely provide a more accurate diagnosis of $\mathrm{AD}$, comparable with the current criteria for the neuropathological classification.

\section{REFERENCES}

[1] Growdon JH. Biomarkers of Alzheimer disease. Arch Neurol 1999; 56: 281-3.

[2] Takeuchi M, Sato T, Takino J, et al. Diagnostic utility of serum or cerebrospinal fluid levels of toxic advanced glycation endproducts (TAGE) in early detection of Alzheimer's disease. Med Hypotheses 2007; 69: 1358-66.

[3] Ward M. Biomarkers for Alzheimer's disease. Expert Rev Mol Diagn 2007; 7: 635-46.

[4] Dubois B, Feldman HH, Jacova C, et al. Research criteria for the diagnosis of Alzheimer's disease: revising the NINCDS-ADRDA criteria. Lancet Neurol 2007; 6: 734-46.

[5] Petersen RC, Doody R, Kurz A, et al. Current concepts in mild cognitive impairment. Arch Neurol 2001; 58: 1985-92.

[6] DeCarli C. Mild cognitive impairment: prevalence, prognosis, aetiology, and treatment. Lancet Neurol 2003; 2: 15-21.

[7] Petersen RC. Mild cognitive impairment as a diagnostic entity. J Intern Med 2004; 256: 183-94.

[8] Blennow K, Hampel H. CSF markers for incipient Alzheimer's disease. Lancet Neurol 2003; 2: 605-13.

[9] Hampel H, Teipel SJ, Fuchsberger T, et al. Value of CSF betaamyloid1-42 and tau as predictors of Alzheimer's disease in patients with mild cognitive impairment. Mol Psychiatry 2004; 9: 705-10.

[10] Maruyama M, Matsui $\mathrm{T}$, Tanji $\mathrm{H}$, et al. Cerebrospinal fluid tau protein and periventricular white matter lesions in patients with mild cognitive impairment: implications for 2 major pathways. Arch Neurol 2004; 61: 716-20.

[11] Galasko D, Chang L, Motter R, et al. High cerebrospinal fluid tau and low amyloid beta42 levels in the clinical diagnosis of Alzheimer's disease and relation to apolipoprotein E genotype. Arch Neurol 1998; 55: 937-45.

[12] Kanai M, Matsubara E, Isoe K, et al. Longitudinal study of cerebrospinal fluid levels of tau, A_1-40, and A_1-42(43) in Alzheimer's disease: a study in Japan. Ann Neurol 1998; 44: 17-26.

[13] Motter R, Vigo-Pelfrey C, Kholodenko D, et al. Reduction of betaamyloid peptide42 in the cerebrospinal fluid of patients with Alzheimer's disease. Ann Neurol 1995; 38: 643-8.

[14] Fagan A, Mintun M, Mach R, et al. Inverse relation between in vivo amyloid imaging load and CSF Abeta42 in humans. Ann Neurol 2006; 59: 512-9.

[15] Andreasen N, Vanmechelen E, Van de Voorde A, et al. Cerebrospinal fluid tau protein as a biochemical marker for Alzheimer's disease: a community based follow up study. J Neurol Neurosurg Psychiatry 1998; 64: 298-305.

[16] Arai H, Terajima M, Miura M, et al. Tau in cerebrospinal fluid: a potential diagnostic marker in Alzheimer's disease. Ann Neurol 1995; 38: 649-52.

[17] Tapiola T, Overmyer M, Lehtovirta M, et al. The level of cerebrospinal fluid tau correlates with neurofibrillary tangles in Alzheimer's disease. Neuroreport 1997; 8: 3961-3.

[18] Buerger K, Ewers M, Pirttila T, et al. CSF phosphorylated tau protein correlates with neocortical neurofibrillary pathology in Alzheimer's disease. Brain 2006; 129: 3035-41.

[19] Engelborghs S, Sleegers K, Cras P, et al. No association of CSF biomarkers with APOEepsilon4, plaque and tangle burden in definite Alzheimer's disease. Brain 2007; 130: 2320-6.

[20] Mares J, Kanovsky P, Herzig R, et al. The assessment of beta amyloid, tau protein and cystatin $\mathrm{C}$ in the cerebrospinal fluid: laboratory markers of neurodegenerative diseases. Neurol Sci 2009; 30: 1-7.

[21] Ikeda S, Yanagisawa N, Allsop D, Glenner GG. Evidence of amyloid beta-protein immunoreactive early plaque lesions in Down's syndrome brains. Lab Invest 1989; 61: 133-7.

[22] Haass C, Schlossmacher MG, Hung AY, et al. Amyloid betapeptide is produced by cultured cells during normal metabolism. Nature 1992; 359: 322-5.

[23] Strozyk D, Blennow K, White LR, Launer LJ. CSF Abeta 42 levels correlate with amyloid-neuropathology in a population-based autopsy study. Neurology 2003; 60: 652-6. 
[24] Hampel H, Bürgerb K, Teipelb SJ, Bokde ALW, Zetterberg H, Blennow K. Core candidate neurochemical and imaging biomarkers of Alzheimer's disease. Alzheimers Dement 2008; 4: 38-48.

[25] Mattsson N, Axelsson M, Haghighi S, et al. Reduced cerebrospinal fluid BACE1 activity in multiple sclerosis. Mult Scler 2009; 15 : 448-54.

[26] Fagan AM, Head D, Shah AR, et al. Decreased cerebrospinal fluid A $\beta 42$ correlates with brain atrophy in cognitively normal elderly. Ann Neurol 2009; 65: 176-83.

[27] Georganopoulou DG, Chang L, Nam JM, et al. Nanoparticle-based detection in cerebral spinal fluid of a soluble pathogenic biomarker for Alzheimer's disease. Proc Natl Acad Sci USA 2005; 102: 22736.

[28] Pitschke M, Prior R, Haupt M, Riesner D. Detection of single amyloid beta-protein aggregates in the cerebrospinal fluid of Alzheimer's patients by fluorescence correlation spectroscopy. Nat Med 1998; 4: 832-4.

[29] Fukuyama R, Mizuno T, Mori S, Nakajima K, Fushiki S, Yanagisawa K. Agedependent change in the levels of Abeta40 and Abeta42 in cerebrospinal fluid from control subjects, and a decrease in the ratio of Abeta42 to Abeta40 level in cerebrospinal fluid from Alzheimer's disease patients. Eur Neurol 2000; 43: 15560 .

[30] Mehta PD, Pirttila T, Mehta SP, Sersen EA, Aisen PS, Wisniewski HM. Plasma and cerebrospinal fluid levels of amyloid beta proteins 1-40 and 1-42 in Alzheimer disease. Arch Neurol 2000; 57: 100-5.

[31] Schoonenboom NS, Mulder C, Van Kamp GJ, et al. Amyloid beta 38,40 , and 42 species in cerebrospinal fluid: more of the same? Ann Neurol 2005; 58: 139-42.

[32] Shoji M, Matsubara E, Kanai M, et al. Combination assay of CSF tau, A beta 1-40 and A beta 1-42(43) as a biochemical marker of Alzheimer's disease. J Neurol Sci 1998; 158: 134-40.

[33] Hansson $\mathrm{O}$, Zetterberg $\mathrm{H}$, Buchhave $\mathrm{P}$, et al. Prediction of Alzheimer's disease using the CSF Abeta42/Abeta40 ratio in patients with mild cognitive impairment. Dement Geriatr Cogn Disord 2007; 23: 316-20.

[34] Portelius E, Zetterberg H, Gobom J, Andreasson U, Blennow K. Targeted proteomics in Alzheimer's disease: focus on amyloidbeta. Expert Rev Proteomics 2008; 5: 225- 37.

[35] Bateman RJ, Munsell LY, Morris JC, Swarm R, Yarasheski KE, Holtzman DM. Human amyloid-beta synthesis and clearance rates as measured in cerebrospinal fluid in vivo. Nat Med 2006; 12: 85661

[36] Hasegawa M. Biochemistry and molecular biology of tauopathies. Neuropathology 2006; 26: 484-90.

[37] Bürger née Buch K, Padberg F, Nolde T, et al. Cerebrospinal fluid tau protein shows a better discrimination in young old ( $<70$ years) than in old old patients with Alzheimer's disease compared with controls. Neurosci Lett 1999; 277: 21-4.

[38] Wahlund LO, Barkhof F, Fazekas F, et al. A new rating scale for age-related white matter changes applicable to MRI and CT. Stroke 2001; 32: 1318-22.

[39] Hampel H, Buerger K, Zinkowski R, et al. Measurement of phosphorylated tau epitopes in the differential diagnosis of Alzheimer disease: a comparative cerebrospinal fluid study. Arch Gen Psychiatry 2004; 61: 95-102.

[40] Buerger K, Zinkowski R, Teipel SJ, et al. Differential diagnosis of Alzheimer's disease with cerebrospinal fluid levels of tau protein phosphorylated at threonine 231. Arch Neurol 2002; 59: 1267-72.

[41] Kohnken R, Buerger K, Zinkowski R, et al. Detection of tau phosphorylated at threonine 231 in cerebrospinal fluid of Alzheimer's disease patients. Neurosci Lett 2000; 287: 187-90.

[42] Vanmechelen E, Vanderstichele $\mathrm{H}$, Davidsson $\mathrm{P}$, et al. Quantification of tau phosphorylated at threonine 181 in human cerebrospinal fluid: a sandwich ELISA with a synthetic phosphopeptide for standardization. Neurosci Lett 2000; 285: 4952.

[43] Itoh N, Arai H, Urakami K, et al. Large-scale, multicenter study of cerebrospinal fluid tau protein phosphorylated at serine 199 for the antemortem diagnosis of Alzheimer's disease. Ann Neurol 2001; 50: $150-6$.

[44] Sjogren M, Davidsson P, Tullberg M, et al. Both total and phosphorylated tau are increased in Alzheimer's disease. J Neurol Neurosurg Psychiatry 2001; 70: 624-30.
[45] Mitchell A, Brindle N. CSF phosphorylated tau: does it constitute an accurate biological test for Alzheimer's disease? Int J Geriatr Psychiatry 2003; 18: 407-11.

[46] Blennow K, Vanmechelen E, Hampel H. CSF total tau, Abeta42 and phosphorylated tau protein as biomarkers for Alzheimer's disease. Mol Neurobiol 2001; 24: 87-97.

[47] Ballatore C, Lee VM, Trojanowski JQ. Tau-mediated neurodegeneration in Alzheimer's disease and related disorders. Nat Rev Neurosci 2007; 8: 663-72.

[48] Hansson O, Zetterberg H, Buchhave P, Londos E, Blennow K, Minthon L. Association between CSF biomarkers and incipient Alzheimer's disease in patients with mild cognitive impairment: a follow-up study. Lancet Neurol 2006; 5: 228-34.

[49] Herukka SK, Hallikainen M, Soininen H, Pirttila T. CSF Abeta42 and tau or phosphorylated tau and prediction of progressive mild cognitive impairment. Neurology 2005; 64: 1294-7.

[50] Mattsson N, Zetterberg H, Hansson O. CSF biomarkers and incipient Alzheimer disease in patients with mild cognitive impairment. JAMA 2009; 302: 385-93.

[51] Zetterberg $\mathrm{H}$, Wahlund LO, Blennow $\mathrm{K}$. Cerebrospinal fluid markers for prediction of Alzheimer's disease. Neurosci Lett 2003; 352: 67-9.

[52] Maddalena A, Papassotiropoulos A, Muller-Tillmanns B, et al. Biochemical diagnosis of Alzheimer disease by measuring the cerebrospinal fluid ratio of phosphorylated tau protein to betaamyloid peptide42. Arch Neurol 2003; 60: 1202-6.

[53] Ibach B, Binder H, Dragon M, et al. Cerebrospinal fluid tau and beta-amyloid in Alzheimer patients, disease controls and an agematched random sample. Neurobiol Aging 2006; 27: 1202-11.

[54] Ewers M, Buerger K, Teipel SJ, et al. Multicentre assessment of CSF-phosphorylated tau for the prediction of conversion of MCI. Neurology 2007; 69: 2205-12.

[55] Zhang J, Goodlett DR, Quinn JF, et al. Quantitative proteomics of cerebrospinal fluid from patients with Alzheimer disease. J Alzheimers Dis 2005; 7: 125-33.

[56] Abdi F, Quinn JF, Jankovic J, et al. Detection of biomarkers with a multiplex quantitative proteomic platform in cerebrospinal fluid of patients with neurodegenerative disorders. J Alzheimers Dis 2006; 9: 293-348.

[57] Ray S, Britschgi M, Herbert C, et al. Classification and prediction of clinical Alzheimer's diagnosis based on plasma signaling proteins. Nat Med 2007; 13: 1359-62.

[58] Knopman DS, DeKosky ST, Cummings JL, et al. Practice parameter: diagnosis of dementia (an evidence-based review). Report of the Quality Standards Subcommittee of the American Academy of Neurology. Neurology 2001; 56: 1143-53.

[59] Cathcart HM, Huang R, Lanham IS, Corder EH, Poduslo SE. Cystatin C as a risk factor for Alzheimer disease. Neurology 2005; 64: 755-7.

[60] Kaeser SA, Herzig MC, Coomaraswamy J, et al. Cystatin C modulates cerebral beta-amyloidosis. Nat Genet 2007; 39: 1437-9.

[61] Shimode K, Kobayashi S, Imaoka K, Umegae N, Nagai A Leukoencephalopathy-related cerebral amyloid angiopathy with cystatin C deposition. Stroke 1996; 27: 1417-9.

[62] Beyer K, Lao JI, Gomez M, et al. Alzheimer's disease and the cystatin $\mathrm{C}$ gene poly-morphism: an association study. Neurosci Lett 2001; 315: 17-20.

[63] Maruyama H, Izumi Y, Oda M, et al. Lack of an association between cystatin $\mathrm{C}$ gene polymorphsms in Japanese patients with Alzheimer's disease. Neurology 2001; 57: 337-9.

[64] Sundelöf J, Arnlöv J, Ingelsson E, et al. Serum cystatin C and the risk of Alzheimer disease in elderly men. Neurology 2008; 71: 1072-9.

[65] Qin W, Ho L, Wang J, Peskind E, Pasinetti GM. S100A7, a novel Alzheimer's disease biomarker with non-amyloidogenic $\alpha$ secretase activity acts via selective promotion of ADAM-10. PLoS ONE 2009; 4: e4183.

[66] Watson PH, Leygue ER, Murphy LC. Psoriasin (S100A7). Int J Biochem Cell Biol 1998; 30: 567-71.

[67] Yin GN, Lee HW, Cho JY, Suk K. Neuronal pentraxin receptor in cerebrospinal fluid as a potential biomarker for neurodegenerative diseases. Brain Res 2009; 1265: 158-70.

[68] Zhong Z, Ewers M, Teipel S, et al. Levels of beta-secretase (BACE1) in cerebrospinal fluid as a predictor of risk in mild cognitive impairment. Arch Gen Psychiatry 2007; 64: 718-26. 
[69] de Leon MJ, DeSanti S, Zinkowski R, et al. Longitudinal CSF and MRI biomarkers improve the diagnosis of mild cognitive impairment. Neurobiol Aging 2006; 27: 394-401.

[70] Davidsson P, Sjögren M. The use of proteomics in biomarker discovery in neurodegenerative diseases. Dis Markers 2005; 21: 81-92.

[71] Simonsen AH, McGuire J, Podust VN, et al. A novel panel of cerebrospinal fluid biomarkers for the differential diagnosis of Alzheimer's disease versus normal aging and frontotemporal dementia. Dement Geriatr Cogn Disord 2007; 24: 434-40.

[72] Finehout EJ, Franck Z, Choe LH, Relkin N, Lee KH. Cerebrospinal fluid proteomic biomarkers for Alzheimer's disease. Ann Neurol 2007; 61: 120-9.

[73] Simonsen AH, McGuire J, Hansson O, et al. Novel panel of cerebrospinal fluid biomarkers for the prediction of progression to Alzheimer dementia in patients with mild cognitive impairment. Arch Neurol 2007; 64: 366-70.
[74] Simonsen AH, McGuire J, Podust VN, et al. Identification of a novel panel of cerebrospinal fluid biomarkers for Alzheimer's disease. Neurobiol Aging 2008; 29: 961-8.

[75] Gustaw-Rothenberg KA, Siedlak SL, Bonda DJ, et al. Dissociated amyloid- $\beta$ antibody levels as a serum biomarker for the progression of Alzheimer's disease: A population-based study. Exp Gerontol 2009; doi:10.1016/j.exger.2009.10.003.

[76] Wiltfang J, Esselmann H, Bibl M, et al. Amyloid beta peptide ratio 42/40 but not Abeta 42 correlates with phospho-Tau in patients with low- and high-CSF A beta 40 load. J Neurochem 2007; 101: 1053-9.

[77] Portelius E, Zetterberg H, Andreasson U, et al. An Alzheimer's disease-specific beta-amyloid fragment signature in cerebrospinal fluid. Neurosci Lett 2006; 409: 215-9.

[78] Blennow K, Wallin A, Hager O. Low frequency of post-lumbar puncture head-ache in demented patients. Acta Neurol Scand 1993; 88: 221-3.

(C) Alessandra Piccini; Licensee Bentham Open.

This is an open access article licensed under the terms of the Creative Commons Attribution Non-Commercial License (http: //creativecommons.org/licenses/by-nc/ $3.0 /$ ) which permits unrestricted, non-commercial use, distribution and reproduction in any medium, provided the work is properly cited. 